\title{
Mesocosm investigation into the effects of bioturbation on the diversity and structure of a subtidal macrobenthic community
}

\author{
Stephen Widdicombe ${ }^{1,2, *}$, Melanie C. Austen ${ }^{1}$ \\ ${ }^{1}$ Centre For Coastal \& Marine Sciences, Plymouth Marine Laboratory, Prospect Place, West Hoe, Plymouth PL1 3DH, \\ United Kingdom \\ ${ }^{2}$ Plymouth Environmental Research Centre, (Department of Biological Sciences), University of Plymouth, Drake Circus, \\ Plymouth PL4 8AA, United Kingdom
}

\begin{abstract}
Benthic mesocosm experiments have highlighted the importance of bioturbation in maintaining levels of diversity and setting community structure in subtidal macrobenthic assemblages. In the mesocosm facility of the Norwegian Institute for Water Research (NIVA) at Solbergstrand, Norway, partitioned boxes of sediment were subjected to continuous disturbance through bioturbation for a period of $20 \mathrm{wk}$. The effect of type and intensity of bioturbation on the macro-infauna was examined by exposing different partitioned areas to different bioturbating species at different densities. The 3 test macrofauna species used were the bivalves Nuculoma tenuis (subsurface deposit feeder) and Abra alba (surface deposit/suspension feeder) at 3 different densities, and the heart urchin Brissopsis lyrifera (subsurface burrowing deposit feeder) at a single density. The presence of $N$. tenuis at low densities resulted in significantly higher levels of $\alpha$ and $\beta$ diversity than were observed in the undisturbed or highly disturbed treatments. Previous experiments have shown that $B$. Iyrifera also elicits a response in the associated fauna consistent with the 'intermediate disturbance hypothesis' Such a response was not observed in the $A$. alba treatments. Multivariate data analysis demonstrated that the response of the associated fauna was influenced by the identity of the organism causing the disturbance. It was also evident that different elements of the community responded differently to bioturbation. This paper makes comparisons between the responses of macrofauna and meiofauna to bioturbation. Our experimental results suggest that the identity, density and distribution of large bioturbating organisms are important factors in the structuring of infaunal communities and in setting and maintaining levels of diversity in apparently homogeneous areas.
\end{abstract}

KEY WORDS: Diversity - Disturbance - Bioturbation - Macrofauna - Meiofauna - Nuculoma tenuis . Abra alba. Brissopsis lyrifera

\section{INTRODUCTION}

Bioturbation is particularly important in controlling chemical, physical and biological processes in marine sediments, especially when the influences of physical disturbances such as wave action or strong currents are minimal. Many authors have highlighted the effects of bioturbation on abiotic variables such as sediment transport (e.g. Rowden \& Jones 1993) and sediment chemistry (e.g. Nedwell \& Walker 1995), and on

·E-mail: s.widdicombe@pml.ac.uk biotic processes such as the structuring of macrobenthic communities (e.g. Sousa 1980, Thistle 1983). It has been suggested that the mechanisms by which bioturbation modifies community structure are through the direct (e.g. predation) and indirect (e.g. sediment disturbance) effects of deposit-feeding macrofauna on the survival of settling and newly settled larval invertebrates (Woodin 1976, Woodin et al. 1998). When these mechanisms are coupled with the temporal and spatial variability of large, deposit-feeding species, it is clear that bioturbation could be responsible for the creation and maintenance of environmental heterogeneity in an otherwise homogeneous environment (Levin \& 
Paine 1974, Levin 1994). The overall effects of bioturbation can be summarised as a type of biotic disturbance to the environment. This realisation has led to a large number of investigations into the precise role of bioturbation in ecosystem processes. However, such studies have either focused on the effect of an individual species (e.g. Hall et al. 1991, Ambrose 1993) or have taken the turnover created by the entire biota as a single environmental variable (e.g. D'Andrea et al. 1996). This approach has ignored the role played by the type of bioturbator causing the disturbance, concentrating instead on bioturbation disturbance as a single, quantifiable unit of damage, and assumes that any response is reliant solely on the size and frequency of disturbance (Petraitis et al. 1989). It is clear that such an assumption cannot be justified until the effects of different bioturbating species are directly compared. Macrofaunal species assemblages are made up of organisms which differ in size, feeding strategy, burrowing activity and mobility. Intuitively it seems unlikely that the activities of these different species will have identical effects on the chemical, physical and biological processes within the sediment. Indeed, a review by Hall (1994) concluded that, with respect to sediment disturbance, species must be judged on their individual characteristics.

Widdicombe \& Austen (1998) demonstrated that intermediate densities of the burrowing heart urchin Brissopsis lyrifera enhanced species diversity in sublittoral sediment assemblages. This species, like many large macrofaunal species, can be extremely patchy, with its abundance varying considerably both spatially and temporally (authors' pers. obs.). B. lyrifera is a nonselective, infaunal deposit feeder with no particulate size selection (Nichols 1959) and should not remove one infaunal species in preference to any other. However, by 'bulldozing' through the sediment it has a major impact on sediment structure and stability. In addition, by creating a shallow respiratory funnel, less than $3 \mathrm{~cm}$ from the sediment surface (De Ridder \& Lawrence 1982), B. Iyrifera increases the depth of oxygenated sediment. Experimental work (Austen \& Widdicombe 1998. Widdicombe \& Austen 1998) suggests that the presence of $B$. lyrifera enhances local heterogeneity and increases $\beta$ diversity. In this study we have chosen 3 test species to compare the effects of their bioturbation on associated communities: B. lyrifera, Nuculoma tenuis and Abra alba. B. lyrifera and the bivalve $N$. tenuis are both subsurface deposit feeders and their feeding activities generate disturbance in the top 2 to $3 \mathrm{~cm}$ of the sediment. It may therefore be expected that bioturbation caused by these 2 species will have the same effect on the community structure of associated fauna. However, B. Iyrifera (mean length $3 \mathrm{~cm}$, mean volume $10.61 \mathrm{~cm}^{3}$ ) is a much larger animal than $N$. tenuis (mean length $0.9 \mathrm{~cm}$, mean volume $0.21 \mathrm{~cm}^{3}$ ) and, as its movements displace more sediment than the bivalve, any community response may differ in magnitude. In contrast, $A$. alba (mean length $1.5 \mathrm{~cm}$, mean volume $0.75 \mathrm{~cm}^{3}$ ) is a surface deposit/suspension feeder that reworks the surface $0.5 \mathrm{~cm}$ and has limited lateral movement. Eagle (1975) reported that a single specimen of $A$. alba, kept in an aquarium, reworked an area of $7 \mathrm{~cm}$ in diameter and raised the sediment surface by $2 \mathrm{~cm}$ during a $4 \mathrm{wk}$ period. The effects of such differences in feeding strategy and mobility on sediment disturbance were addressed by Thayer (1983). This author concluded that, on the basis of maximum recorded volumetric rates, 'biological bulldozing' is the most effective form of bioturbation and the effects of sediment ingestion or egestion are probably less important. It therefore seems likely that different community responses will occur when assemblages are subjected to disturbance by these different bioturbators.

The organisms chosen as bioturbating agents for this study exhibit large natural variations in abundance, both spatially and temporally. Eagle (1975) observed Abra alba densities of 1220 and 3200 ind. $\mathrm{m}^{-2}$. Dauvin et al. (1993) also observed large fluctuations in the populations of $A$. alba in the English Channel and southern North Sea. At Gravelins the population ranged between 0 and 8907 ind. $\mathrm{m}^{-2}$ over a $14 \mathrm{yr}$ period, whilst at Rade de Lorient the variability was even greater with the population ranging from 200 to 17900 ind $\mathrm{m}^{-2}$ in the period 1982 to 1984 . The temporal variability of another Abra species, A. nitida, at a site in the southern North Sea, was highlighted by Watson et al. (1996). At this site the abundance of A. nitida generally varied from between 100 and 1000 ind. $\mathrm{m}^{-2}$ over a 3 yr period; however, on 1 sampling occasion in December 1992 the bivalve density was in excess of 10000 adult ind. $\mathrm{m}^{-2}$. Such variability has also been observed in the densities of the other 2 test species. Harvey \& Gage (1995) recorded densities of Nuculoma tenius between 417 and 2231 ind. $\mathrm{m}^{-2}$ over a 2 yr period in Loch Etive, Scotland. Ursin (1960) reported densities of Brissopsis Iyrifera in the North Sea to be as high as 60 ind. $\mathrm{m}^{-2}$. Such variability in the abundance of these bioturbating species may be very important in establishing environmental heterogeneity and diversity. The experimental densities used in this study were selected to be realistic representations of naturally occurring conditions.

It is important to consider the whole benthic assemblage when assessing community effects. Previous work by Warwick et al. (1990) and Warwick (1984) suggested that meiofaunal organisms responded differently to sediment disturbance than macrofaunal organisms. This was explained by resource partitioning or competition amongst macrofauna being most 
influenced by the availability of space, whilst for meiofauna it is the availability of specialised food resources that is of greatest importance. Hence, disruption of physical structuring within the sediment by bioturbators will have a greater effect on the macrofauna than on the meiofauna.

The current study uses mesocosm experiments to compare the effects of 3 species, Brissopsis lyrifera, Abra alba and Nuculoma tenuis, on the diversity and community structure of the associated fauna. Such comparisons will enable the importance of disturbance type and intensity to be observed. With reference to previous investigations (Austen \& Widdicombe 1998, Austen et al. 1998), the response of a macrofaunal community to bioturbation will be directly compared to that of a meiofaunal community.

\section{METHODS}

Experimental design. The experiment was carried out in the mesocosm at the NIVA marine research station Solbergstrand, Oslofjørd, Norway (Berge et al. 1986). Experimental design and procedures have previously been described (Austen et al. 1998) and are summarised here. A Day grab enabled sampling to concentrate on the surface sediment where the majority of the small infauna resides. Four $1 \mathrm{~m} \times 1 \mathrm{~m}$ boxes were filled to a depth of $30 \mathrm{~cm}$ with a fresh, sandy-mud sediment collected from Bjørhodenbukta, a sheltered bay in the inner part of Oslofjørd. The boxes were placed in a $5 \mathrm{~m} \times 7 \mathrm{~m}$ indoor, epoxy-resin-coated concrete basin and the sediment was allowed to settle for 9 d. A constant water depth of $100 \mathrm{~cm}$ was maintained using an open circulation sea water supply drawn from $60 \mathrm{~m}$ depth from the fjord and allowing it to run to waste. After the sediment had settled, each box was partitioned into 14 small areas of $81.7 \mathrm{~cm}^{2}$ and 2 large areas of $176.7 \mathrm{~cm}^{2}$ using mesh cages. The dimensions and construction of the cages is illustrated in Fig. 1a. Each cage was positioned in the box so that it was equidistant from its nearest neighbour and from the edge of the box (Fig. 1b), ensuring that each cage was surrounded by the same amount of undisturbed sediment. The 2 large partitioned areas were positioned randomly within the grid. Cages were pushed down into the sediment until they sat on the floor of the box with approximately $10 \mathrm{~cm}$ of mesh protruding from the sediment surface. This prevented any of the large bioturbating animals from escaping. Nuculoma tenuis and Brissopsis lyrifera were collected ( 3 to 10 April 1995) using a Day grab at the sediment collection site in Bjørhodenbukta. Abrá alba were supplied by Kristineberg Marine Research Station, Sweden (4 April 1995) and were collected in Ellös Fjord on the Swedish west

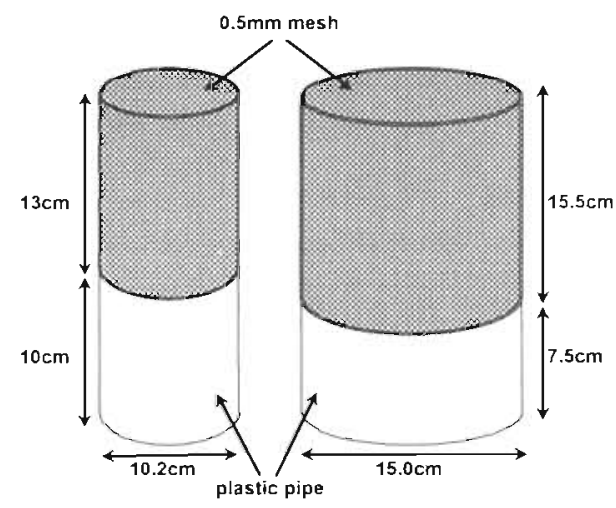

a.

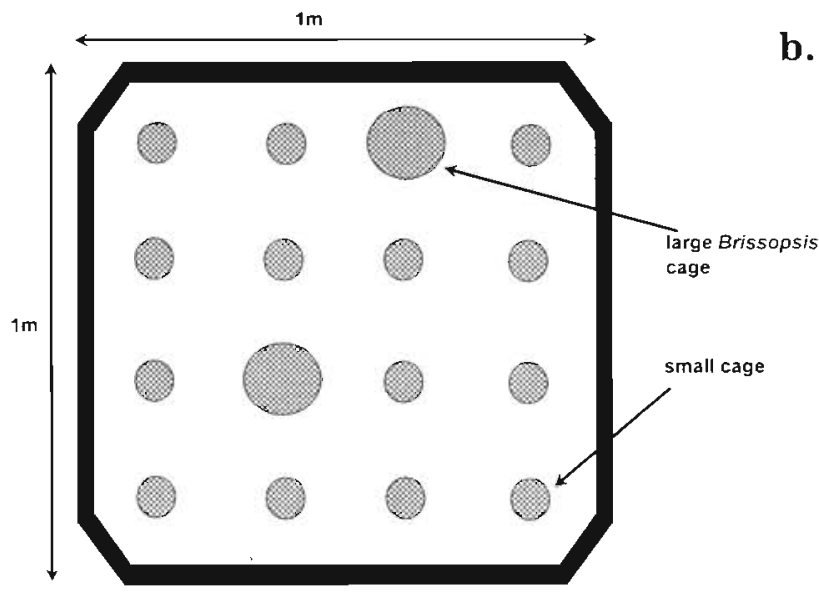

Fig. 1 (a) Design and dimensions of small and large cages. (b) Layout of cages in each of 5 replicate $1 \mathrm{~m}^{2}$ boxes in the mesocosm. Positions of the 2 large cages and treatments were randomly allocated

coast, from a mud clay sediment with shell debris in $11 \mathrm{~m}$ depth, using a $0.5 \mathrm{~m}$ Agassiz dredge. The bioturbating macrofauna were held in the mesocosm basin prior to their addition to the cages (12 April 1995). Controls and 7 treatments were duplicated in each of the 4 boxes of sediment. The treatments consisted of $\mathrm{Nu}$ culoma low, Nuculoma mid, Nuculoma high, Abra low, Abra mid, Abra high and Brissopsis. (Table 1). B. lyrifera is much larger than the 2 bivalve species and, therefore, due to restricted sediment area available for experimentation, only 1 density of this species was studied. Two treatment areas in each box were controls consisting of partitioned areas where no additional macrofauna were added. Samples were taken on 29 August 1995, 20 wk after the start of the experiment. This duration was considered long enough to ensure the community had time to respond to the disturbance whilst being short enough to remove the need to provide additional food for the bioturbators.

Sampling. Plastic cores $10 \mathrm{~cm}$ in diameter were used to take a sample from each treatment and control area, 
Table 1. Quantity of bioturbators used per treatment expressed as number of individuals per core, equivalent number of individuals per meter squared and total volume of bioturbating organisms per meter squared

\begin{tabular}{|c|c|c|c|c|c|c|c|c|c|}
\hline & \multicolumn{3}{|c|}{ Nuculoma tenuis } & \multicolumn{3}{|c|}{ Abra alba } & \multicolumn{3}{|c|}{ Brissopsis lyrifera } \\
\hline & $\begin{array}{l}\text { Density } \\
\left(\text { core }^{-1}\right)\end{array}$ & $\begin{array}{c}\text { Density } \\
\left(\mathrm{m}^{-2}\right)\end{array}$ & $\begin{array}{c}\text { Volume } \\
\left(\mathrm{cm}^{3} \mathrm{~m}^{-2}\right)\end{array}$ & $\begin{array}{l}\text { Density } \\
\left({\left.\text { cor } e^{-1}\right)}^{2}\right.\end{array}$ & $\begin{array}{c}\text { Density } \\
\left(\mathrm{m}^{-2}\right)\end{array}$ & $\begin{array}{c}\text { Volume } \\
\left(\mathrm{cm}^{3} \mathrm{~m}^{-2}\right)\end{array}$ & $\begin{array}{l}\text { Density } \\
\left(\text { core }^{-1}\right)\end{array}$ & $\begin{array}{c}\text { Density } \\
\left(\mathrm{m}^{-2}\right)\end{array}$ & $\begin{array}{l}\text { Volume } \\
\left(\mathrm{cm}^{3} \mathrm{~m}^{-2}\right)\end{array}$ \\
\hline Low & 5 & 612 & 128 & 5 & 612 & 459 & - & - & - \\
\hline Mid & 15 & 1836 & 308 & 12 & 1469 & 1377 & - & - & - \\
\hline High & 25 & 3304 & 642 & 25 & 3304 & 2478 & 1 & 57 & 604 \\
\hline
\end{tabular}

in each of the 4 boxes. These samples were sieved over a $250 \mu \mathrm{m}$ mesh to retain the juvenile macrofauna, since these young individuals may be more susceptible to the effects of disturbance than larger, more established animals. The residue was fixed in a $10 \%$ formaldehyde solution and sorted under a binocular microscope. All animals were extracted and identified to the lowest possible taxonomic level. The remainder of the sediment in the cages was coarsely sieved to quantify the Abra alba, Nuculoma tenuis and Brissopsis lyrifera in the partitioned areas at the end of the experiment. The bivalves were then immersed in $10 \%$ formic acid to remove the shell before being blotted and weighed.

Data analysis. Diversity measures: The PRIMER software package was used to generate the diversity indices for number of species, species richness, evenness and Shannon Wiener. A Kruskal-Wallace test was used to test for significant differences between treatments for the means of these indices. This nonparametric method was preferred because, unlike ANOVA, it makes no assumptions based on variance or normality. The BioDiversity Pro package was used to calculate rarefaction values (Hurlbert 1971) for each of the treatments. These values enable comparisons of $\alpha$ diversity to be made which are independent of the number of individuals per sample or treatment.

Species area curves were constructed using the BioDiversity Pro software package (Natural History Museum and the Scottish Association of Marine Science). The slope of these curves indicates differences in species turnover, a measure of $\beta$ diversity, with a steeper curve being representative of higher diversity. This technique has previously been used to examine the relationship between disturbance rate, colonisation rate and species turnover (Holt 1992, Caswell \& Cohen 1993). He \& Legendre (1996) reviewed the uses of species-area relationships and concluded that care should be taken when using such curves as considerable theoretical assumptions are made (such as infinite, homogeneous assemblage area) that cannot be met in the real world. The mean Bray-Curtis dissimilarities within treatments were calculated as an indication of the extent of within treatment variability. This can be used as a measure of $\beta$ diversity with greater heterogeneity being indicative of higher $\beta$ diversity. An index of multivariate dispersion (Warwick \& Clarke 1993, Somerfield \& Clarke 1997) was calculated to quantify the variability within and between treatments.

Community structure analysis: Multivariate data analyses followed the methods described by Clarke (1993) using the PRIMER software package. Using the Bray-Curtis similarity measure, analysis was carried out on untransformed and double square root $(\sqrt{ } \sqrt{ })$ transformed data. The former identified changes in dominant species whilst $\sqrt{ }$ transformation is a balanced approach which increases the influence of low abundance species. Although using $\sqrt{ }$ transformed data is not a direct observation of the rare fauna, by comparing the results obtained from the 2 transformations it is possible to examine the influence of rare species on the overall community pattern. Two-way crossed ANOSIM (Clarke 1993) was carried out to test for box effects. Where none were detected, 1 -way pairwise ANOSIM was used to test for significant differences $(p<0.05)$ between macrofaunal assemblages in different treatments. RELATE (Clarke \& Warwick 1994) was used to test for differences in the way communities respond to increasing densities of the different bivalves. When comparing MDS ordinations using this method, a significant result indicates that the patterns observed in the 2 ordinations are the same.

\section{RESULTS}

\section{Experimental design}

The environmental conditions within the mesocosm basin remained constant throughout the experiment (salinity of $34.5 \pm 0.5$ psu; temperature of $7 \pm 1^{\circ} \mathrm{C}$ ). Survival of the bioturbating species was 91,95 and $100 \%$ for Nuculoma tenuis, Abra alba and Brissopsis lyrifera respectively. The control treatments contained no $A$. alba or $B$. lyrifera; however, $N$. tenuis was present in 2 of the control treatments as a result of the species being present at the sediment collection site. This species was represented by 2 small individuals in one of the control treatments and a single small 
individual in another. These numbers were considered small enough as to allow these treatments to still be considered as controls. Two-way crossed ANOSIM and ANOVA results indicated no significant box effects for either multivariate or univariate data analysis ( $\mathrm{p}>0.05)$.

\section{Diversity measures}

$\alpha$ diversity

Results demonstrate that Nuculoma tenuis elicits an 'intermediate disturbance type' response, with the low $\mathrm{Nu}$ culoma treatments having a significantly greater number of species per sample than either the control or high Nuculoma treatments (Fig. 2, Table 1).

This response is not related to any change of abundance, as the number of individuals per sample in the control, and each of the 3 Nuculoma density treatments were not significantly different. Low Nuculoma treatments were significantly more diverse than all Abra and Brissopsis treatments. The diversity (numbers of species) was significantly reduced in the Brissopsis and high Abra treatments compared to the control and all Nuculoma treatments. Pairwise results from a Kruskal-Wallis analysis indicated that there were no significant differences between treatments for evenness or Shannon Wiener (using logel diversity measures. For species richness, the low Nuculoma treatments were significantly more diverse than the low Abra, mid Abra, high Abra and Brissopsis treatments $(p=0.007,0.005,0.009$ and 0.001 respectively).
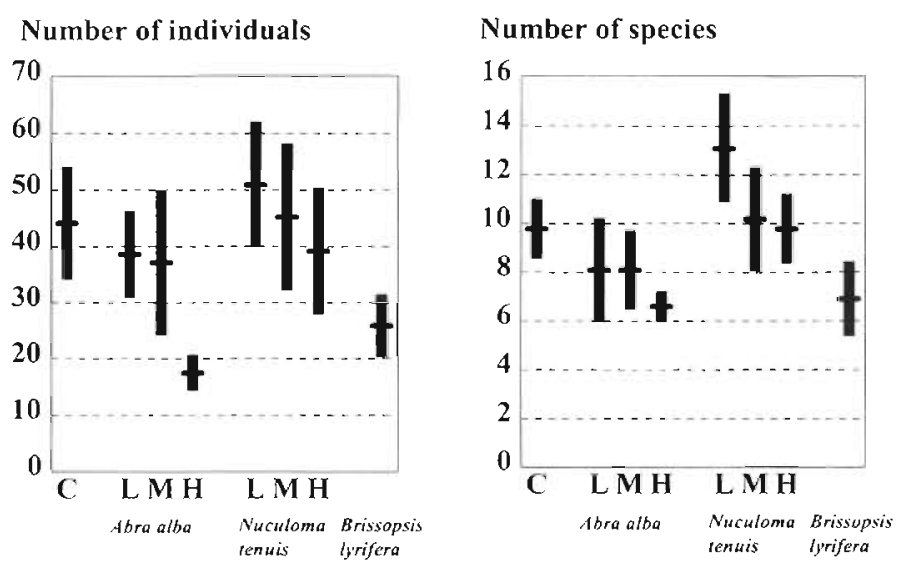

Fig. 2. Mean numbers of individuals and species among controls and treatments, with $95 \%$ confidence intervals
The relationships between the decalcified blotted wet weight of each of the 2 bivalve species and the number of species (NS) per sample is demonstrated in Fig. 3. It can be seen that NS was highest in the low Nuculoma treatments and declined as the bivalve abundance increased. For Abra, the maximum NS is observed in the control treatments and the rate of decline in species number is low. At low values of bivalve biomass, the number of species is higher in Nuculoma treatments compared to treatments with an equivalent weight of Abra.

Results from rarefaction show Nuculoma tenuis again displays an 'intermediate disturbance type' response with the highest diversity occurring in the low treatments (Table 3 ). This increase in diversity at intermediate levels of disturbance is also seen in the Abra treatments; however, the result is made less clear by the high values of ES(101) calculated for high Abra treatments.

\section{$\beta$ diversity}

Fig. 4 demonstrates the differences in species turnover ( $\beta$ diversity) and total number of species between the treatments. Currently, it is not possible to test for significant differences between these curves; however, obvious trends can be seen in these data. The low Nuculoma and control treatments display greater $\beta$ diversity than the other treatments, with the Brissopsis treatment showing very low turnover. The trend for both $N$. tenius and Abra alba is for turnover to decrease as bioturbator abundance increases 


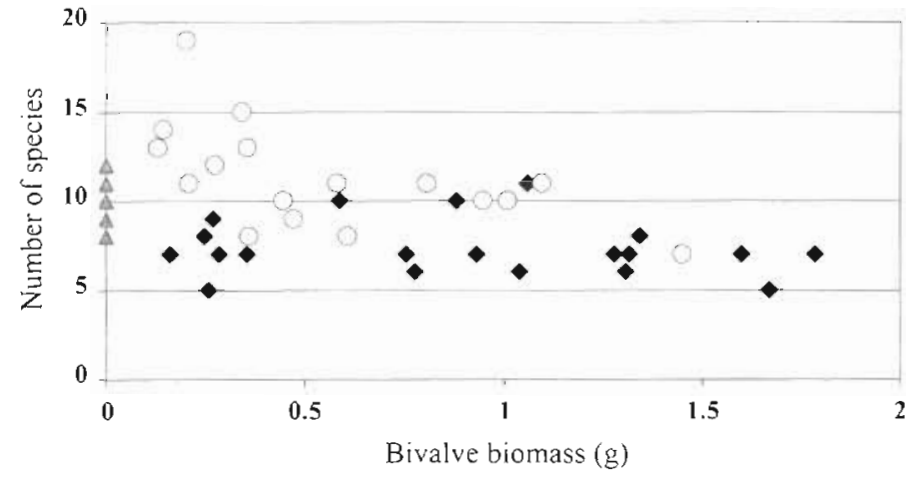

Fig. 3. Number of species present at different densities of each of the 2 bivalve species, as measured by decalcified blotted wet weight.

$(\triangle)$ Control; (O) Nuculoma; ( Abra

From the Bray-Curtis dissimilarity values calculated on untransformed data (Table 4 ), it can be seen that bioturbation by both bivalve species increases $\beta$ diversity of the dominant fauna. The presence of Brissopsis lyrifera at this experimental density reduces $\beta$ diver-

Table 3. Expected number of species present in 101 individuals, ES(101), for different types and densities of bioturbator

\begin{tabular}{|lccc|}
\hline & Nuculoma tenuis & Abra alba & Brissopsis lyrifera \\
\hline Control & 16.02 & 16.02 & 16.02 \\
Low & 19.53 & 16.45 & - \\
Mid & 15.45 & 15.1 & - \\
High & 14.8 & 18.47 & 13.52 \\
\hline
\end{tabular}

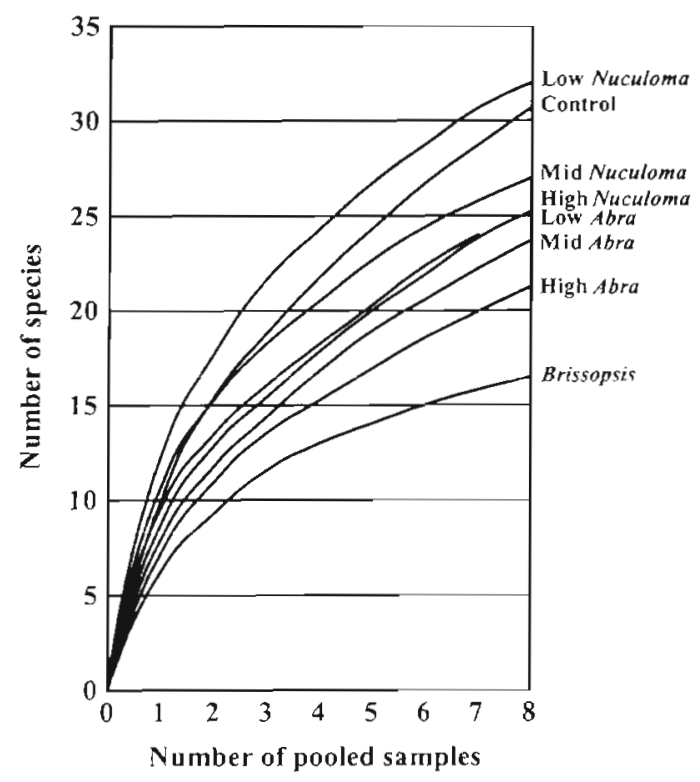

Fig. 4. Species area curves from combined replicates for treatments and controls, based on 100 random sorts
Table 4. Mean Bray-Curtis dissimilarities indicating differences in variability within treatments using untransformed and $\sqrt{ }$ transformed data

\begin{tabular}{|lcc|}
\hline & Untransformed & $\sqrt{ } \sqrt{ }$ transformed \\
\hline Control & 36.33 & 43.98 \\
Low Abra & 48.08 & 53.45 \\
Mid Abra & 39.51 & 49.05 \\
High Abra & 49.24 & 49.90 \\
Low Nuculoma & 38.57 & 43.88 \\
Mid Nuculoma & 41.25 & 42.36 \\
High Nuculoma & 38.96 & 35.62 \\
Brissopsis & 32.83 & 44.06 \\
\hline
\end{tabular}

sity. The dominant fauna show an intermediate disturbance type response in the Nuculoma treatments with the maximum dissimilarity value occurring in the mid Nuculoma treatment. In the case of $A b r a_{\text {, }}$ both the low and high treatments display elevated dissimilarity values compared with the controls. The results from the $\sqrt{ }$ transformed data show a different pattern is occurring in the rarer species. This element of the fauna shows an intermediate disturbance type response in the Abra treatments, with the maximum dissimilarity value occurring in the low Abra treatment. In the Nuculoma treatments, the $\beta$ diversity of the rarer species declines as the intensity of disturbance increases. The dissimilarity values in the Brissopsis treatment also differs between transformations. Using $\downarrow \checkmark$ transformed data, the rarer species diversity increases slightly whereas the untransformed data indicated that the dominant species diversity decreased.

In areas disturbed by Nuculoma tenius, variability in community structure between replicates was greatest in the low Nuculoma treatment (Table 5). This increase in variability at intermediate levels of disturbance was also seen in the Abra treatments; however, the result was less clear due to the high values of dispersion in the high Abra treatments.

Table 5. MVDISP results indicating differences in variability, using untransformed and $W$ transformed data, between (a) Nuculoma and (b) Abra treatments

\begin{tabular}{|c|c|c|c|c|}
\hline & Control & Low & Mid & High \\
\hline \multicolumn{5}{|c|}{$\begin{array}{l}\text { (a) Values for multivariate dispersion for Nuculoma } \\
\text { treatments }\end{array}$} \\
\hline $\begin{array}{l}\text { No data transformation } \\
\sqrt{ } \text { data transformation }\end{array}$ & $\begin{array}{l}0.91 \\
1.04\end{array}$ & $\begin{array}{l}1.21 \\
1.14\end{array}$ & $\begin{array}{l}1.02 \\
0.99\end{array}$ & $\begin{array}{l}0.76 \\
0.59\end{array}$ \\
\hline \multicolumn{5}{|c|}{ (b) Values for multivariate dispersion for Abra treatments } \\
\hline No data transformation & 0.69 & 119 & 0.86 & 1.27 \\
\hline$\sqrt{ }$ data transformation & 0.75 & 1.19 & 1.00 & 1.11 \\
\hline
\end{tabular}




\section{Community structure}

Disturbance intensity effects

The ANOSIM results (Table 6) show that there were significant differences between control and bioturbated areas in most cases. These differences occur both in the dominant fauna (untransformed data) and in the rarer species $(\sqrt{ }$ transformed data). The only significant differences observed between different intensities of treatment were between low and high Abra treatments, and between mid and high Abra treatments. The fact that these differences were only observed in the untransformed data implies that these differences are due to changes in the abundance of the dominant species. Differences in community structure were observed when ANOSIM was used to compare control areas with areas disturbed by Brissopsis tenuis. These differences were significant for both the untransformed $(\mathrm{R}=0.296, \mathrm{p}=0.001)$ and $\mathcal{W}$ transfor$\operatorname{med}(\mathrm{R}=0.415, \mathrm{p}=0.000)$ data.

\section{Effects of different bioturbating species}

A global ANOSIM, comparing samples disturbed by Nucloma tenuis with those disturbed by $A b r a$ alba, indicated a significant difference in the $\sqrt{ }$ transformed data $(R=0.153, p=0.001)$. Pairwise comparisons of treatments with different bioturbating species (Table 7 ) highlight the differences between the dominant fauna and the rarer species. Significant differences in the untransformed data were limited to the high Abra comparisons, whilst for $\sqrt{ }$ transformed data, the low Nuculoma treatment was significantly different to both the mid and high Abra treatments

Table 8 indicates that there are no significant differences between Brissopsis treatments and any of the Abra treatments using either untransformed or $\sqrt{ }$ transformed data. Significant differences were observed between the Brissopsis treatments, and both the low and mid Nuculoma treatments for untransformed data. However, heavier $\sqrt{ } \sqrt{ }$ transformation only produces a significant difference between Brissopsis and low Nuculoma.

Using RELATE, a significant result for untransformed data $(R=0.906, p=0.000)$ indicated that the dominant species of an assemblage will respond to increasing intensity of disturbance in the same way
Table 7. R-values from pairwise comparisons of treatments with different bioturbating species using 1-way ANOSIM. Bold values indicate significant differences, $\mathrm{p}<0.05$ ( $\mathrm{p}$-values in parentheses)

\begin{tabular}{|lrr|}
\hline & Untransformed & $\sqrt{ }$ transformed \\
\hline Low Abra vs Low Nuculoma & $-0.068(0.796)$ & $0.107(0.117)$ \\
Low Abra vs Mid Nuculoma & $-0.099(0.910)$ & $-0.075(0.751)$ \\
Low Abra vs High Nuculoma & $-0.145(0.941)$ & $-0.047(0.620)$ \\
Mid Abra vs Low Nuculoma & $0.133(0.084)$ & $\mathbf{0 . 2 4 6}(\mathbf{0 . 0 0 2 )}$ \\
Mid Abra vs Mid Nuculoma & $0.051(0.238)$ & $0.131(0.115)$ \\
Mid Abra vs High Nuculoma & $-0.113(0.816)$ & $-0.008(0.500)$ \\
High Abra vs Low Nuculoma & $\mathbf{0 . 5 6 1 ( 0 . 0 0 2 )}$ & $\mathbf{0 . 4 3 1 ( 0 . 0 0 0 )}$ \\
High Abra vs Mid Nuculoma & $\mathbf{0 . 4 9 6 ( 0 . 0 0 3 )}$ & $0.143(0.114)$ \\
High Abra vs High Nuculoma & $\mathbf{0 . 2 7 0 ( 0 . 0 3 9 )}$ & $0.132(0.162)$ \\
\hline
\end{tabular}

Table 8. R-values from pairwise comparisons of Brissopsis treatments with different intensities of bivalve treatments using 1-way ANOSIM. Bold values indicate significant differences, $p<0.05$ ( $p$-values in parentheses)

\begin{tabular}{|lrr|}
\hline & Untransformed & W transformed \\
\hline Brissopsis vs Low Nuculoma & $\mathbf{0 . 4 4 9}(\mathbf{0 . 0 0 2})$ & $\mathbf{0 . 3 6 0 ( \mathbf { 0 . 0 0 2 } )}$ \\
Brissopsis vs Mid Nuculoma & $\mathbf{0 . 3 0 2 ( \mathbf { 0 . 0 1 2 } )}$ & $0.091(0.182)$ \\
Brissopsis vs High Nuculoma & $0.084(0.235)$ & $0.076(0.269)$ \\
Brissopsis vs Low Abra & $0.114(0.094)$ & $-0.042(0.666)$ \\
Brissopsis vs Mid Abra & $0.022(0.362)$ & $0.101(0.135)$ \\
Brissopsis vs High Abra & $0.063(0.186)$ & $-0.018(0.562)$ \\
\hline
\end{tabular}

regardless of which bivalve species disturbs the sediment. For the less abundant fauna $(\sqrt{ }$ transformed data) the pattern of community response to different levels of disturbances differs between Abra and Nuculoma treatments $(\mathrm{R}=0.188, \mathrm{p}=0.404)$. This indicates that the 2 elements of the community respond in different ways in the presence of different bioturbators and that it is the rarer species which are most influenced by the agent of bioturbation. 


\section{Individual species response}

SIMPER revealed the 8 species most responsible for the differences between treatments observed during multivariate analysis on the untransformed data. The abundance of Chaetozone setosa, Heteromastus filiformis and Eteone flava per sample generally decreased as the amount of disturbance increased. Pholoe minuta abundance increased in response to increased disturbance by Nuculoma tenuis, but decreased in response to increased Abra alba disturbance. Pseudopolydora paucibranchiata and Ophelina acuminata had maximum abundances in low Nuculoma treatments, as did small individuals of Nuculoma, which were already present in the sediment before the addition of the larger $N$. tenuis individuals used to bioturbate the sediment. One species, Cossura longocirrata, increased in abundance as disturbance by both $N$. tenuis and $A$. alba increased. The effect of the species Brissopsis lyrifera was to increase the numbers of $C$. longocirrata and $N$. tenuis but cause a decrease in the average abundance of the other species.

Seventy-one percent of the taxa identified from this experiment was considered as rare, being represented by less than 10 individuals in the experiment as a whole. Of these rare species over half $(55 \%)$ were represented in the treatments of 1 bivalve species but not both (20\% present in Abra treatments but not in NuCuloma treatments; $35 \%$ present in Nuculoma treatments but not in Abra treatments). Almost two thirds of the rare species $(65 \%)$ were absent from the control treatments. The raw data are presented in Appendix 1.

\section{DISCUSSION}

All $\alpha$ diversity (mean number of species per sample. rarefaction) and most $\beta$ diversity (species/area curves, Bray Curtis dissimilarities, multivariate dispersion), were higher in the low density Nuculoma treatments than in the control, mid or high density Nuculoma treatments. This response is similar to that observed in previous work which examined the effects of different densities of Brissopsis lyrifera (Widdicombe \& Austen 1998). It is evident that both $B$. lyrifera and $N$. tenuis cause diversity to increase at an intermediate level of bioturbation. To accept that this response fits the 'Intermediate Disturbance Hypothesis' (Connell 1978) it must first be established that areas of subtidal sediments are subjected to competitive interactions. Whilst there is no direct evidence that competition for space exists (Peterson 1979, Wilson 1990), Pearson \& Rosenberg (1987) suggested that macrofaunal communities are subjected to the pressure of competition during the colonisation of defaunated or disturbed sediments.
Further evidence that bioturbation reduced competitive exclusion was provided by an experiment conducted by Kukert (1991) which imitated the mounds created by deposit-feeding megafauna. These mounds reduced the abundance of the dominant species, suggesting that burial disturbance may play a role in structuring the macrofaunal community by promoting the coexistence of rarer species. Levin et al. (1991) also suggested that, for certain species, sediment mounds act to promote spatial heterogeneity and, perhaps, coexistence. The current study also saw a reduction in the abundance of most of the dominant species in moderately bioturbated areas, coupled with an increase in the total number of species.

Both abundances and number of species in low Nuculoma treatments were greater than those in the control even though there is limited recruitment in the mesocosm system used (Berge et al. 1986). The results suggest that the presence of $N$. tenuis affected the associated macrofaunal community in one of two ways. Firstly, low $N$. tenuis densities may have either enhanced survivorship in the mesocosm and/or encouraged migration of small macrofauna into the partitioned areas from the surrounding sediment. Alternatively, competition between species may have taken place in the undisturbed controls where there were no bioturbators which could check the activities of the dominant species. This competition could potentially drive less effective competitors to extinction, resulting in a reduction in the number of species. These explanations are not mutually exclusive and it is possible that the true effect could be a combination of the two. Assuming that competition does occur in subtidal sediment communities it seems likely that the response of a community to the disturbance caused by 'bulldozing' macrofaunal species, such as Brissopsis lyrifera and $N$. tenuis, does fit the 'Intermediate Disturbance Hypothesis'.

Whilst the reduction of competitive exclusion is the most likely explanation of the responses observed within this study, it is important to be aware of other possible processes acting on the community. The majority of the dominant species were reduced in bioturbated sediments compared to the undisturbed areas; however, there were some species that increased in number in moderately disturbed conditions. This suggests that the test species may have altered the quality of the sedimentary environment in various ways, proving beneficial to some species but displacing others. The increased diversity at intermediate levels of bioturbation may therefore be due to the effect of bioturbation on the sediment rather than the physical disruption of dominant species. This explanation, unlike the 'Intermediate Disturbance Hypothesis', is not reliant on the existence of competitive exclusion. 
When examining diversity and community level responses it is evident that the agent of bioturbation is extremely important in structuring the associated macrofaunal assemblage (Hall 1994). Brissopsis lyrifera and Nuculoma tenuis, both mobile, sub-surface deposit feeders, produced similar 'intermediate disturbance type responses in the associated fauna. However, the present study has been unable to demonstrate such a response induced by the less mobile, surface deposit/suspension-feeding bivalve Abra alba. A possible reason for this may be that the intensity of disturbance in the low Abra treatments was greater than the intensity required to elicit the 'intermediate disturbance type' response. This is possible because, even though the densities and biomass of the 2 bivalve species were similar in the low treatments, $A$. alba occupies more space than $N$. tenuis (mean volumes 0.75 and $0.21 \mathrm{~cm}^{3}$ respectively). The consequence of this size difference is that the equivalent volume of $A$. alba in the low treatments was $459 \mathrm{~cm}^{3} \mathrm{~m}^{-2}$ compared to $128 \mathrm{~cm}^{3} \mathrm{~m}^{-2}$ of $N$, tenuis. A previous experiment by Widdicombe \& Austen (1998) demonstrated an 'intermediate disturbance type' response at densities of $B$. lyrifera which corresponded to $297 \mathrm{~cm}^{3} \mathrm{~m}^{-2}$, which was again lower than the value for the low Abra treament. It is therefore evident that when assessing the potential impact of bioturbating species it may be necessary to consider the amount of space the organism occupies within the sediment as well as its mobility and abundance. Alternatively, it may be that our results are an indication that the intermediate disturbance response does not occur for all types of bioturbation. In support of this, Thayer (1983) indicated that the 'biological bulldozing' of species such as $B$. lyrifera and $N$. tenuis is a more effective form of bioturbation than the ingestion/egestion activities of species such as $A$. alba. This could mean that, before the realisation of any beneficial effects on diversity, of reduced competition due to intermediate levels of sediment disturbance, high densities of $A$. alba will result in overwhelming competition for food.

Multivariate analysis (ANOSIM and RELATE) also demonstrated distinct differences in the way the different elements of the associated community responded to different agents of bioturbation and to changes in disturbance intensity. Results show that it is the rare species which are most affected by different types of bioturbators. This is corroborated by a recent field study which examined how a subtidal, sediment community was spatially structured and the possible factors which controlled this. Kendall \& Widdicombe (1999) analysed spatial patterns of different size fractions in the benthic community. They suggested that in sediments structured by biotic processes, variability in the densities of large bioturbating organisms will affect the abundance of the dominant species in the medium size range. This may lead to a possible reduction in the pressure of competition in such bioturbated areas and hence provide an opportunity for rarer species to survive. Comparisons of the fauna in the Abra treatments with that in the Nuculoma treatments suggest that the identity of the rare species, benefiting from such a reduction in competitive pressure, can be influenced by the identity of the bioturbating organism causing the disturbance. Kendall \& Widdicombe (1999) made comparisons of bioturbated sediments with physically structured sediments which indicated increased spatial variability in the small-sized species of the communities in bioturbated sediment. This variability was shown to exist in the rarer, lower abundance species rather than the dominant, constantly present species. The low abundance, small-bodied fauna formed a patchwork of assemblages, each with different species compositions. These field data and our mesocosm results imply that biological mediation of the sediment is a vital element in the maintenance of diversity.

A comparison of the responses of the meiofauna and macrofauna to bioturbation illustrates some interesting similarities. Univariate measures of nematode assemblace structure (e.g. number of species, species richness, Shannon Wiener diversity) were affected by the intensity of disturbance in a way that conforms to the intermediate disturbance hypothesis, although it is not known whether competition is the mechanism for this. Higher macrofaunal $\beta$ diversity in the low Nuculoma treatments of this experiment and the low Brissopsis treatments of Widdicombe \& Austen (1998), compared to the control treatment, were also consistent with the predictions of the intermediate disturbance hypothesis. However, it was evident, particularly from changes in the number of species and abundance, that macrobenthic assemblages were more strongly affected by disturbance than the meiofauna. This was consistent with the hypotheses of Warwick et al. (1990) which were used to explain differences in the macro- and meiofauna communities in Hamilton Harbour, Bermuda. Univariate measures of the meiofaunal nematode response to the different bioturbating species did not differentiate between the different types of disturbance in the present experiment. Multivariate analysis indicated that the nematode species response in the community was much more sensitive to the type of disturbance but less sensitive to the intensity of disturbance treatments compared to the control (Austen et al. 1998). In the macrofauna the response was similar to that of the meiofauna with the identity of the species witrin an assemblage being mostly influenced by the type of bioturbator which caused the disturbance.

Despite the different feeding modes of the macrofauna disturbers, Austen et al. (1998) did not observe 
any specific response from the nematodes that could be related to the likely sediment depth at which the macrofaunal disturbers would have greatest impact. Except at the highest bivalve densities, there was no indication that the effects of the bioturbation arose through direct general predation or mortality caused by sediment disturbance, as there was almost no significant effect on nematode abundances in any of the treatments. Significantly lower macrofaunal abundances were observed in the highest densities of all 3 of the test species. This again indicated that if direct mortality did occur it would most likely be due to a combination of extreme disturbance and intense competition for food. At low and mid densities, the disturbance activity of the macrofauna test species may stimulate microbial growth (e.g. Hargrave 1970, Aller \& Yingst 1985, Krantzberg 1985) and increase sediment oxygenation (e.g. Flint \& Kalke 1986) providing an increase in food and spatial resources which directly affects the nematodes and some small macrofaunal species. It is possible that the macrofauna/meiofauna relationship may be a series of feedback loops. For example, changes in the meiofauna may influence the elements of the macrofauna which interact with meiofauna. Similarly, the macrofauna test species may have indirectly influenced the meiofauna by aitering the community structure of the associated macrofauna which in turn may be more selective predators or feeding competitors of the meiofauna.

The findings from this and previous studies have highlighted the importance of bioturbation in structuring macrofaunal and meiofaunal communities and setting levels of diversity in apparently homogenous environments. To date, however, the experiments have been limited to single species treatments. In order to fully understand the processes which structure benthic communities it is essential to expand on this information in the form of field experiments and field studies. These should not only examine the effects that different combinations of bioturbators will have on an associated assemblage but should also address the factors which control the distributions, abundance and potential interactions of the bioturbating species themselves.

Acknowledgements. This work was enabled by a grant from the EC Large Scales Facility Programme, was funded in part by the UK Ministry of Agriculture, Fisheries and Food (project No AE1113), and is a contribution to the PML Coastal Biodiversity research project. We thank Torgeir Bakke, John Arthur Berge, Liv Berge and Joanna Maloney of NIVA, Oslo, for helping to facilitate this work, to Hakkon Oen, Einar Johannesen and Oddbjorn Pettersen for their technical support at the Solbergstrand Marine Station and to the crew of the RV 'Trygve Braarud' We are also very grateful to Mike Kendall, Malcolm Jones and Richard Warwick for constructive com- ments and discussions during the preparation of this manuscript. We gratefully acknowledge the constructive input of Lisa Levin and 2 anonymous referees. Additionally, we thank Bob Clarke and Martin Carr for statistical advice. The BioDiversity software package was kindly supplied by Neil McAleece of the Natural History Museum.

\section{LITERATURE CITED}

Aller RC, Yingst JY (1985) Effects of the marine deposit-feeders Heteromastus filiformis (Polychaeta), Macoma balthica (Bivalvia), and Tellina texana (Bivalvia) on averaged sediment solute transport, reaction rates, and microbial distributions. J Mar Res 43:615-645

Austen MC, Widdicombe S (1998) Experimental evidence of effects of the heart urchin Brissopsis lyrifera on associated subtidal meiobenthic nematode communities. J Exp Mar Biol Ecol 222(1/2):219-238

Austen MC, Widdicombe S, Villano N (1998) Effect of biological disturbance on diversity and structure of a nematode meiobenthic community. Mar Ecol Prog Ser 174:233-246

Berge JA, Schaanning $M$, Bakke $T$, Sandøy $K$, Skeie GM, Ambrose WG Jr (1986) A soft-bottom sublittoral mesocosm by the Oslofjord: description, performance and examples of application. Ophelia 26:37-54

Caswell $H_{1}$ Cohen JE (1993) Local and regional regulation of species-area relations: a patch-occupancy model. In: Ricklefs RE, Schluter D (eds) Species diversity in ecological communities: historic and geographic perspectives. University of Chicago Press, Chicago, p 99-107

Clarke KR (1993) Non-parametric multivariate analyses of changes in community structure. Aust J Ecol 18:117-143

Clarke KR, Warwick RM (1994) Changes in marine communities: an approach to statistical analysis and interpretation. Plymouth Marine Laboratory, Plymouth

Connell JH (1978) Diversity in tropical rain forests and coral reefs. Science 199:1302-1309

D'Andrea AF, Lopez GR, Craig NI (1996) Benthic macrofauna and depth of bioturbation in Eckernfoerde Bay, southwestern Baltic Sea. Geo-Mar Lett 16(3):155-159

Dauvin JC, Dewarumez JM, Elkaim B, Bernardo B, Fromentin JM, Ibanez F (1993) Cinétique de Abra alba (mollusque bivalve) de 1977 à 1991 en Manche-Mer du Nord, relation avec les facteurs climatiques. Oceanol Acta 16:413-422

De Ridder C, Lawrence JM (1982) Food and feeding mechanisms: Echinoidea. In: Jangoux M, Lawrence JM (eds) Echinoderm nutrition. AA Balkema, Rotterdam, p 57-115

Eagle RA (1975) Natural fluctuations in a soft bottom benthic community. J Mar Biol Assoc UK 55(4):865-878

Flint RW, Kalke RD (1986) Biological enhancement of estuarine benthic community structure. Mar Ecol Prog Ser 31: $23-33$

Hall SJ (1994) Physical disturbance and marine benthic communities: life in unconsolidated sediments. Oceanogr Mar Biol Annu Rev 32:179-239

Hall SJ, Basford DJ, Robertson MR, Raffaelli DG, Tuck I (1991) Patterns of recolonisation and the importance of pit-digging by the crab Cancer pagunus in a subtidal sand habitat. Mar Ecol Prog Ser 72:93-102

Hargrave BT (1970) The effect of deposit feeding amphipods on the metabolism of benthic micro-flora. Limnol Oceanogr 15:21-36

Harvey R, Gage JD (1995) Reproduction and recruitment of Nuculoma tenuis (bivalvia:nuculoida) from Loch Etive, Scotland. J Molluscan Stud 61:409-419 


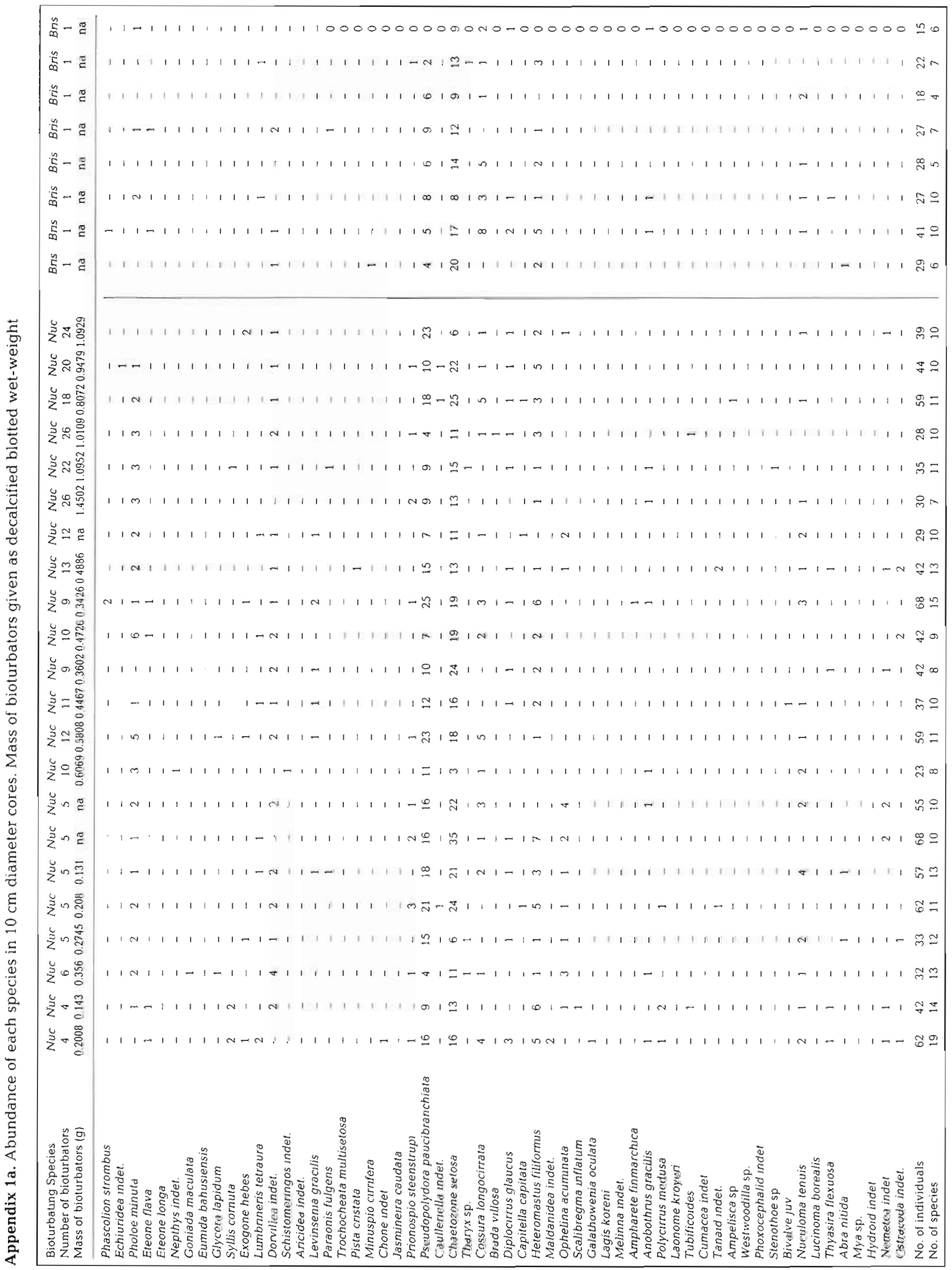




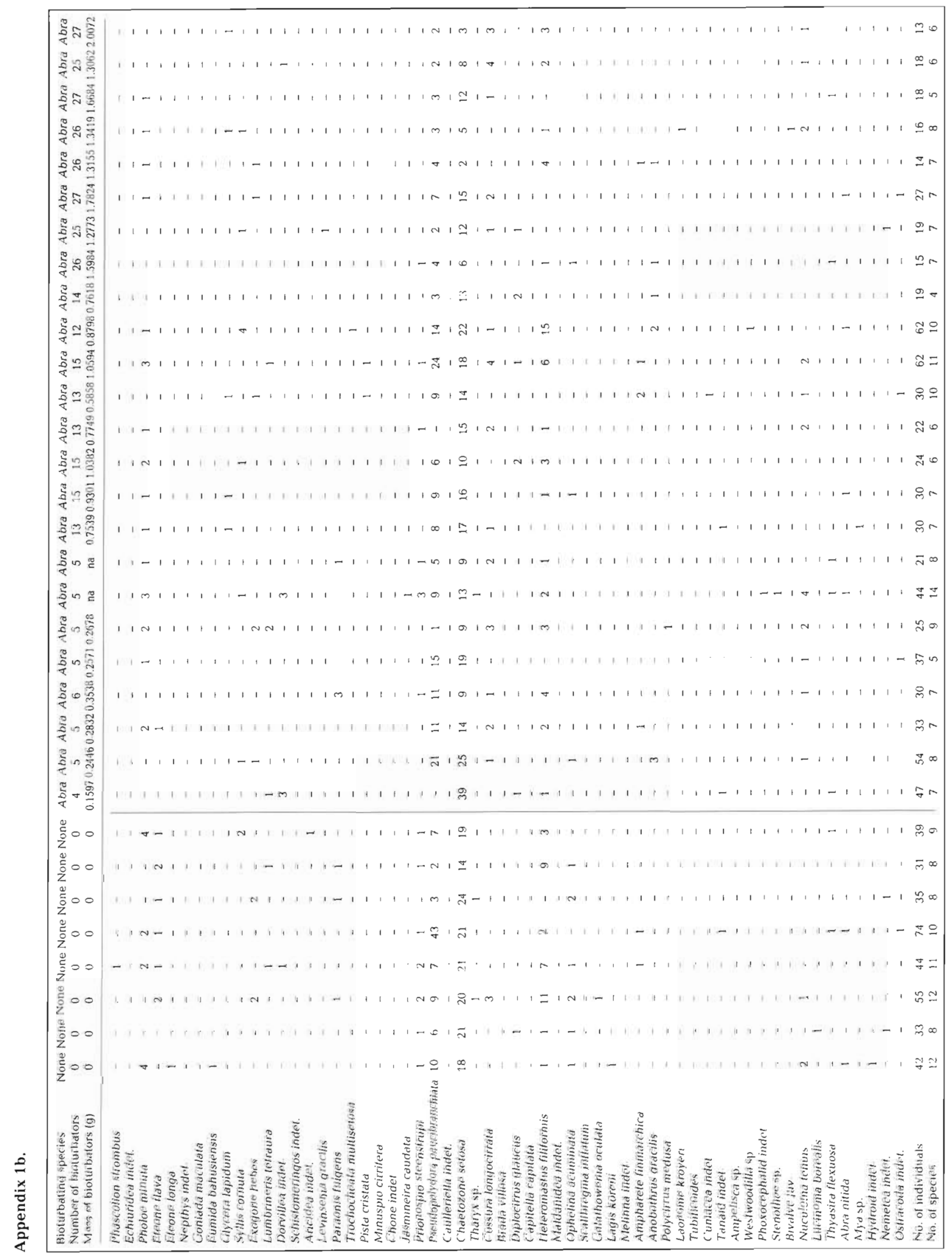


He F, Legendre P (1996) On species-area relations. Am Nat 148:719-737

Holt RD (1992) A neglected facet of island biogeography: the role of internal spatial dynamics in area effects. Theor Popul Biol 41:354-371

Hurlbert SH (1971) The non-concept of species diversity: a critique and alternative parameters. Ecology 52:577-586

Kendall MA, Widdicombe S (1999) Small scale patterns in the structure of macrofaunal assemblages of shallow soft sediment. J Exp Mar Biol Ecol 237:127-140

Krantzberg G (1985) The influence of bioturbation on physical, chemical and biological parameters in aquatic environments: a review. Environ Pollut A Ser Ecol Biol 39(2):99-122

Kukert H (1991) In situ experiments on response of deep-sea macrofauna to burial disturbance. PAC-SCI 45(1):95p

Levin SA (1994) Patchiness in marine and terrestrial systems: from individuals to populations. Phil Trans R Soc Lond B 343:99-103

Levin SA, Paine RT (1974) Disturbance, patch formation and community structure. Proc Natl Acad Sci USA 71(7): $2744-2747$

Levin LA, Childers SE, Smith CR (1991) Epibenthic, agglutinating foraminiferans in the Santa Catalina Basin and their response to disturbance. Deep-Sea Res 38:465-483

Nedwell DB, Walker TR (1995) Sediment-water fluxes of nutrients in an Antarctic coastal environment: influences of bioturbation. Polar Biol 15(1):57-64

Nichols D (1959) Changes in the chalk heart-urchin Micraster interpreted in relation to living forms. Phil Trans Roy Soc B $242: 347-437$

Pearson TH, Rosenburg R (1987) Feast and famine: structuring factors in marine benthic communities. In: Gee JHR, Giller PS (eds) The 27th Symposium of the British Ecological Society - Organization of Communities Past and Present, p 373-395

Peterson $\mathrm{CH}$ (1979) Predation, competitive exclusion and diversity in the soft-sediment benthic communities of estuaries and lagoons. In: Livingston RJ (ed) Ecological processes in coastal and marine systems. Plenum Press, New York, p 233-264

Petraitis PS, Latham RE, Niesenbaum RE (1989) The maintenance of species diversity by disturbance. $Q$ Rev Biol 64: $393-418$

Rowden AA, Jones MB (1993) Critical evaluation of sediment

Editorial responsibility: Otto Kinne (Editor)

Oldendorf/Luhe, Germany turnover estimates for Callianassidae (Decapoda: Thalassinidea). J Exp Mar Biol Ecol 173(2):265-272

Somerfield PJ, Clarke KR (1997) A comparison of some methods commonly used for the collection of sublittoral sediments and their associated fauna. Mar Environ Res 43(3): $145-156$

Sousa WP (1980) The responses of a community to disturbance: the importance of successional age and species life histories. Oecologia 45:72-81

Thayer CW (1983) Sediment-mediated biological disturbance and the evolution of marine benthos. In: Tevesz MJS, McCall PL (eds) Biotic interactions in recent and fossil benthic communities. Plenum Press, New York, p 479-625

Thistle D (1983) The role of biologically produced habitat heterogeneity in deep-sea diversity maintenance. Deep-Sea Res 30(12A): 1235-1245

Ursin E (1960) A quantitative investigation of the echinoderm fauna of the central North Sea. Meddr Danm Fisk Havunders $2: 1-204$

Warwick RM (1984) Species size distributions in marine benthic communities. Oecologia 61:32-41

Warwick RM, Clarke KR (1993) Increased variability as a symptom of stress in marine communities. J Exp Mar Biol Ecol 172:215-226

Warwick RM, Platt HM, Clarke KR, Agard J, Gobin J (1990) Analysis of macrobenthic and meiobenthic community structure in relation to pollution and disturbance in Hamilton Harbour, Bermuda. J Exp Mar Biol Ecol 138:119-142

Watson PG, Widdicombe S, Frickers PE (1996) Heterogeneity in macrobenthic activity. Final report for DOE contract No 7/7/423, Plymouth Marine Laboratory, Plymouth

Widdicombe S, Austen MC (1998) Experimental evidence for the role of Brissopsis lyrifera (Forbes 1841) as a critical species in the maintenance of benthic diversity and the modification of sediment chemistry. I Exp Mar Biol Ecol 228(2):241-255

Wilson WH Jr (1990) Competition and predation in marine soft-sediment communities. Annu Rev Ecol Syst 21:221-241

Woodin SA (1976) Adult-larval interactions in dense infaunal assemblages: patterns of abundance. J Mar Res 34(1): $25-42$

Woodin SA, Marinelli RL, Lindsay SM (1998) Process-specific cues for recruitment in sedimentary environments: geochemical signals? J Mar Res 56(2):535-558

Submitted: March 15, 1999; Accepted: June 10, 1999

Proofs received from author(s): November 5, 1999 